\title{
Unraveling Microbial and Edaphic Factors Affecting the Development of Sudden Death Syndrome in Soybean
}

\author{
Ali Y. Srour, Department of Plant, Soil and Ag. Systems, Southern Illinois University, Carbondale 62901; David J. \\ Gibson, Department of Plant Biology, Southern Illinois University, Carbondale 62901; Leonor F. S. Leandro, \\ Department of Plant Pathology and Microbiology, lowa State University, Ames 50011; Dean K. Malvick, \\ Department of Plant Pathology, University of Minnesota, St. Paul 55108; and Jason P. Bond and Ahmad M. \\ Fakhoury, ${ }^{\dagger}$ Department of Plant, Soil and Ag. Systems, Southern Illinois University, Carbondale 62901
}

Accepted for publication 27 June 2017.

\begin{tabular}{|c|c|}
\hline \multicolumn{2}{|c|}{ ABSTRACT } \\
\hline $\begin{array}{l}\text { Sudden death syndrome (SDS) caused by Fusarium } \\
\text { virguliforme is a widespread and economically important disease } \\
\text { of soybean. SDS is typically distributed unevenly in patches across } \\
\text { soybean fields. While certain spots in fields are highly conducive to } \\
\text { the development of severe SDS, other areas appear to be naturally } \\
\text { healthy or suppressive to the disease. The role of soil microbial } \\
\text { communities and soil physical and chemical properties in SDS } \\
\text { development was investigated in } 45 \text { soybean fields in Illinois, lowa, } \\
\text { and Minnesota. Soil samples were collected from symptomatic } \\
\text { patches in fields and from adjacent areas where SDS foliar } \\
\text { symptoms did not develop. Multiple edaphic factors were } \\
\text { measured, and markers specific to bacteria, fungi, archaea, } \\
\text { oomycete, and nematodes, coupled with Illumina MiSeq } \\
\text { sequencing, were used to identify key taxa likely associated with } \\
\text { SDS development. A total of } 14,200,000 \text { reads were mapped }\end{array}$ & $\begin{array}{l}\text { against the National Center for Biotechnology Information } \\
\text { nucleotide database and taxonomically compared using } \\
\text { Metagenome Analyzer (MEGAN5). Physical and chemical } \\
\text { analysis of soil variables did not provide any correlation with the } \\
\text { patchiness pattern of SDS. Significant differences in bacterial and } \\
\text { fungal community structure between soils from healthy and } \\
\text { diseased areas of fields were found. At least } 20 \text { taxa were } \\
\text { associated with healthy soils, including members of Fusarium } \\
\text { oxysporum sp. complex, Actinomycetales, Firmicutes, Chloroflexi, } \\
\text { Trichoderma spp., Pseudomonas, Metacordyceps, Penicillium, } \\
\text { Purpureocillium, and Myceliophtora. In diseased soils, Fusarium } \\
\text { solani spp., Phallus rugulosus, Stachybotrys, and Alpha- and } \\
\text { Betaproteobacteria dominated. Our results suggest that the } \\
\text { relative abundance of multiple microbial taxa in the soil plays a key } \\
\text { determinant in the incidence of SDS. }\end{array}$ \\
\hline
\end{tabular}

Sudden death syndrome (SDS) caused by the fungus Fusarium virguliforme (Aoki et al. 2003) can result in severe losses of soybean yields, and is ranked among the top five economically important diseases of soybean in the United States (Hartman et al. 2015a, b; Wrather and Koenning 2006). The disease occurs frequently in Illinois, Iowa, and Minnesota, and has increased in incidence in soybean production fields in the Midwest of the United States (Wrather and Koenning 2006, 2009). F. virguliforme is a soilborne pathogen that colonizes the rhizosphere in the early growth stages of soybean (Njiti et al. 1998). However, foliar symptoms, including chlorosis and necrosis, are mostly expressed in middle to late season. Disease symptoms may progress to premature defoliation of leaves in severe

${ }^{\dagger}$ Corresponding author: A. M. Fakhoury; E-mail address: amfakhou@ siu.edu

*The $e$-Xtra logo stands for "electronic extra" and indicates that five supplementary figures and six supplementary tables are published online.

(C) 2017 The American Phytopathological Society cases of disease (Roy et al. 1997; Rupe et al. 1997). Moreover, SDS typically develops in patches in production fields.

SDS management approaches are limited and focus on the use of host resistance with partially resistant cultivars. Resistance in these cultivars may not be durable in the long run due to pathogen population shifts in virulence (Gray and Achenbach 1996; Li et al. 2009; Malvick and Bussey 2008). Currently, there are no foliar chemical applications that can be used to control SDS. This is, in part, because the pathogen resides in the roots of infected plants. Fungicidal seed treatments have emerged as a new option to manage SDS. ILeVO, developed by Bayer CropScience, is a seed treatment that proved to be effective for managing SDS. Soybean seeds treated with ILeVO have been shown to reduce $F$. virguliforme population densities in the roots and to have reduced foliar SDS symptoms (Islam et al. 2015; Kandel et al. 2015). In addition, employing cultural practices focused on delaying planting date, deep tillage and rotation with nonhost crops may reduce the risk of SDS (Kantartzi et al. 2012; Vick et al. 2006). Several reports have shown SDS to interact synergistically with Heterodera glycines, the soybean cyst nematode (SCN) (McLean and Lawrence 1995; Roy 
et al. 1997; Wrather and Koenning 2009; Xing and Westphal 2013). However, in a contrasting report, the association between $H$. glycines and $F$. virguliforme populations in the soil were found to be inversely correlated (Gao et al. 2006).

Cultural practices in fields, while aimed at overcoming soil deficiencies and enhancing plant health, also affect soil biota. In many instances, the net effect of these practices has been shown to be inconsistent in terms of reducing disease severity and enhancing plant growth. This inconsistency may be due to a lack of understanding of the mechanisms involved and how these practices affect the native soil microbiota (Kloepper et al. 1999).

Hence, there is renewed interest in the study of naturally diseasesuppressive soils. This reemerging area of research could increase management options for SDS. Suppressive soils and the active microbes in them have the potential to provide crop producers sustainable and environmentally friendly tools to manage diseases (Baker and Cook 1982; Mazzola 2002, 2004; Weller et al. 2002). A disease suppressive soil is one in which disease is suppressed even when the pathogen is present in the rhizosphere of a susceptible host. Baker and Cook (1982) denote a soil as suppressive "where the pathogen does not establish or persist, establishes but causes little or no damage, or establishes and causes disease for a while but thereafter the disease is less important, although the pathogen may persist in the soil."

Soil suppressiveness can be either general or specific. General suppression is considered as a basal level of defense provided by the collective activity of the soil microbiome against a wide variety of pathogens, whereas specific suppression is thought to be provided by a specific group of microbes that are antagonistic against specific plant pathogens. Only specific suppression can be transferred to conducive soils (Ryan et al. 2009; Weller et al. 2002). Soil suppressiveness of various pathosystems involving prokaryotes, oomycetes, ascomycetes, basidiomycetes, streptomycetes, hyphomycetes, and plant-parasitic nematodes has been widely reported in diverse crops (Alabouvette 1986; Broadbent and Baker 1974; Chen 2007; Chet and Baker 1980; Cook and Rovira 1976; Curl 1963; Kok et al. 2001; Murakami et al. 2000; Nishiyama et al. 1999, Persson et al. 1999; Pyrowolakis et al. 2002; Weibelzahl-Fulton et al. 1996; Westphal and Becker 2001). For SDS, disease suppression was reported in Indiana in a long-term continuous monoculture of soybean (Westphal and Xing 2011; Xing and Westphal 2009).

Several groups documented abiotic factors that favor SDS development. In particular, temperature and moisture have been noted to play a prominent role (Rupe and Gbur 1995). In the greenhouse, cool soil temperatures promote root rot symptoms, whereas foliar symptoms tend to be more severe at warmer temperatures (GongoraCanul and Leandro 2011; Scherm and Yang 1999). Furthermore, wet crop growing seasons appear to correlate with increasing SDS incidence (Leandro et al. 2012; Roy et al. 1997).

The effect of soil physical and chemical variables on SDS has been found to be puzzling. In Arkansas, SDS severity was found to be favored by high levels of $\mathrm{P}$, organic matter, $\mathrm{CEC}, \mathrm{Ca}, \mathrm{Mg}$, and $\mathrm{Na}$ (Rupe and Gbur 1995; Rupe et al. 1993). In contrast, K levels were found to correlate positively with SDS severity in Iowa (Scherm et al. 1998). Interestingly, application of $\mathrm{KCl}$ decreased disease symptoms and seemed to suppress SDS, while higher sand content and $\mathrm{pH}$ increased disease severity (Howard et al. 1992; Sanogo and Yang 2001). So far, mechanisms involved in SDS incidence and severity have been difficult to associate consistently with physical and chemical variables and with cultural practices. Regional variations and within field variations of SDS incidence and severity compel a more comprehensive analysis involving biological soil variables, whose effects remain poorly understood.

In our study, we identified fields in Illinois, Iowa, and Minnesota that exhibited severe SDS symptoms, while adjacent fields, or spots within the same field, exhibited a certain level of suppression to SDS. Here, we use the term "healthy" for soils with relatively absent SDS symptoms, and "diseased" for soils with moderate to severe SDS symptoms. Our objective was to identify factors associated with the development of SDS. We used a metaprofiling approach along with physical and chemical analyses of soil samples to impartially identify some of the factors affecting SDS incidence and suppression in soybean production fields.

\section{MATERIALS AND METHODS}

Soil sample collection. Soil was collected from visually diseased and healthy patches in soybean fields at growth stage R6 in Illinois, Minnesota, and Iowa in 2010, 2011, and 2012. The geographical locations of sampling sites are shown in Figure 1. Disease incidence was determined as the percentage of plants infected with SDS in the surveyed areas. Foliar symptoms severity was assessed on a scale of 0 to 9 as the percentage of leaf area showing interveinal chlorosis and necrosis (0, healthy to 9 , premature death) (Aoki et al. 2005).

Soybean fields with SDS disease patches averaging at least $10 \mathrm{~m}$ in diameter were selected, and at least 10 fields per state were selected each year. GPS coordinates were recorded at the center of each disease patch. Twenty soil samples (diseased soil) were taken with probes within each SDS hotspot or patch. An additional 20 soil samples (healthy soil) were taken outside the diseased patch (hotspot) from a symptomless area $3 \mathrm{~m}$ beyond the edge of the hotspot and along a transect covering the opposite sides of the SDS patch. Soils were taken at a depth of $30 \mathrm{~cm}$, close to the roots, using a stainless-steel probe. Soil cores from the diseased site in each individual field were combined and mixed. Similarly, soil cores from the healthy sites were combined and mixed. This resulted in two composite samples representing the diseased or healthy sites in each field. Soils were homogenized, sieved to remove plant debris, and stored at $-20^{\circ} \mathrm{C}$ in 50-ml plastic tubes for microbial analysis, and in plastic bags at room temperature for physical and chemical analyses. Soil samples with high moisture content were air dried for $24 \mathrm{~h}$ before further processing.

Microbial community analysis. To study the microbiome structure in soils collected from field areas with and without SDS, we used a culture-independent approach. This approach used the following six steps. (i) Extraction of total DNA from soils collected from healthy and diseased areas; (ii) targeted amplification of DNA markers for bacteria, archaea, fungi, oomycetes, and nematodes; (iii) high throughput sequencing of amplicons using Illumina MiSeq; (iv) de novo assembly and sequence clustering into reference sequences; (v) BLASTN against the NCBI-NT database (Zhang et al. 2000); and (vi) taxonomy classification and construction of phylogenetic trees as well as statistical analysis. Each step is described in detail below.

DNA extraction from soil. Total DNA was extracted from three 250-mg subsamples from each of the 90 composite soil samples using the PowerLyzer PowerSoil DNA kit (MO BIO Laboratories Inc., Carlsbad, CA) per the manufacturer's protocol with minor modifications (Srour et al. 2017). The concentration and quality of each DNA sample was determined using a Nanophotometer P-30 (Implen, Munich, Germany) and agarose gel electrophoresis (Bio-Rad, Hercules, CA). Equimolar amounts of DNA from each composite mixture were pooled together for downstream PCR. DNA samples $(n=90)$ were stored at $-20^{\circ} \mathrm{C}$ for subsequent applications.

Selection of DNA markers and PCR. We used a combination of nine genetic markers (loci) to characterize the microbes in the soil samples. For fungi, the loci included: the nuclear rRNA internal transcribed spacer (ITS), the translation elongation factor 1 alpha gene $(\mathrm{EF}-1 \alpha)$, the large subunit (LSU), and the intergenic spacer (IGS) region. The primer sets used were ITS1 and ITS4 for the ITS 
region (White et al. 1990), EF1 and EF2 for the EF1 a region (Geiser et al. 2004), LR2R/LR3 for LSU D2, and L12R/IGS2R1 for the IGS region (James et al. 2006; Vilgalys and Hester 1990). Our choice for bacterial and archaeal profiling was the V3/4 region, a short informative locus within the 16Sr RNA gene. For the V3 region we used the 341F/518R primer set from Muyzer et al. (1993), and for the $\mathrm{V} 4$ region we used the $515 \mathrm{~F} / 806 \mathrm{R}$ primer set from Bergmann et al. (2011). Both sets give an amplicon below 250 bp in size, which is suitable to obtain sequences of pair end reads on the MiSeq platform.

For nematodes, we used the small subunit (SSU) rDNA and the large subunit (LSU) rDNA regions. The primer set of Blaxter (1998) SSU18A (5'-AAAGATTAAGCCATGCATG-3') and SSU9R (5' AGCTGGAATTACCGCGGCTG-3') were used to amplify a $590 \mathrm{bp}$ of the SSU loci. The primer sets of Nunn et al. (1996) D3A (5'GACCCGTCTTGAAACACGGA-3') and D3B (5'-TCGGAAGGA ACCAGCTACTA-3') were also used to amplify the D3 region of the large subunit (LSU) rDNA. For oomycetes, the ITS region was targeted using UN-up18S42 (5'-CGTAACAAGGTTTCCGTAGGT GAAC-3') (Bakkeren et al. 2000) and UN-lo28S22 (5'-GTTTCTT TTCCTCCGCTTATTGATATG-3') (Lévesque and De Cock 2004).

PCR was used to amplify markers for the above mentioned microbial groups. Equimolar amounts of DNA (50 ng) were used in all PCR reactions. A negative control consisting of no DNA template was used to check for contamination, and a positive control consisting of an appropriate microbe (bacteria, E. coli; fungi, $F$. virguliforme; oomycete, Pythium; nematode, $H$. glycines) was included as well. All PCR conditions and primers used for barcoding microbial communities and nematodes were as previously described in the references

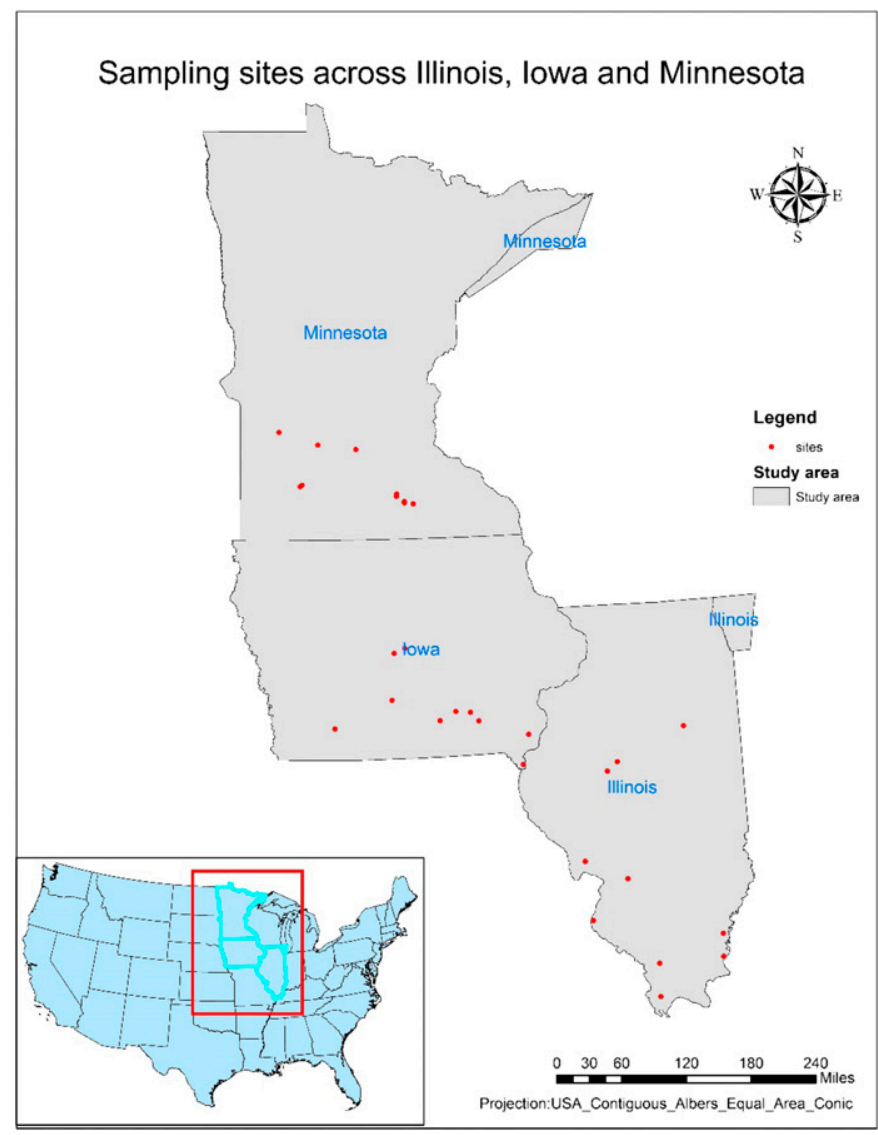

Fig. 1. Map of sampling sites across states of Illinois, lowa, and Minnesota. Red dots represent geographic locations of sampling sites. mentioned above. PCR samples were checked on a $1 \%$ agarose gel with GelRed (Biotium, Fermont, CA) to assess the quality of the amplification. PCR samples were stored at $-20^{\circ} \mathrm{C}$ until sequencing.

Amplicon library construction and sequencing. Amplicon libraries were constructed targeting the markers described above. Amplicons were quantified using a nanophotometer P-30. To investigate taxa variance between diseased and healthy soils, we created two amplicon pools (diseased versus healthy) for each state (Illinois, Iowa, and Minnesota) during each year. Amplicons from diseased and healthy samples were separately combined in equimolar amounts at each location (state) and used downstream in a pool-seq approach (Supplementary Fig. S1). The PCR product pools were each purified using a Qiaquick PCR purification kit (Qiagen, Valencia, CA), and the final concentration was determined using a Qubit Fluorometer (Invitrogen, Life Technologies, NY). Construction of DNA libraries and sequencing on the MiSeq platform were carried out at the Roy J. Carver Biotechnology Center, University of Illinois at UrbanaChampaign (UIUC). The DNA libraries were constructed from $10 \mathrm{ng}$ of amplicon DNA with the TruSeq DNA Sample Prep kit (Illumina, $\mathrm{CA})$, starting at the end-repair step and with one modification: adaptors were diluted 1:20 with $10 \mathrm{nM}$ Tris. The individually barcoded libraries were run on a High-Sensitivity DNA chip in the Bioanalyzer (Agilent, $\mathrm{CA}$ ) to confirm the absence of free primers and primer dimers and to confirm the presence of DNA fragments of the expected size range. Libraries were pooled in equimolar concentration and the pool was quantitated by qPCR on a Bio-Rad CFX Connect Real-Time System (Bio-Rad Laboratories). The pooled libraries were sequenced on a MiSeq platform for 251 cycles from each end of the fragments with a MiSeq sequencing kit 500 cycles version 2. The fastq files were generated and demultiplexed with the Casava 1.8 pipeline (Illumina).

Assembly of reads and microbial community analysis. MiSeq $P E$ reads were de-multiplexed, quality filtered to remove low quality reads, and then trimmed to remove adaptors using the CLC genomics workbench 8.5 (Qiagen Bioinformatics, Redwood City, CA). Quality filtered reads were compared against the NCBI-NT database using BLASTN with an E-score cutoff value of $<10^{-4}$ and a percent identity of at least $90 \%$. MEGAN was then used to compute and explore the taxonomical content of the data set, employing the NCBI taxonomy to summarize and order the results; blast hits of reads were assigned a taxon ID based on NCBI taxonomy. The lowest common ancestor (LCA) algorithm used in MEGAN allowed species-specific sequences to be assigned to taxa near the leaves of the NCBI tree, whereas conserved sequences not assigned to a taxon were pushed up the taxonomy tree until a node of high-order taxa is reached. Finally, a summary of the results of taxa assignments is produced at different ranks of the NCBI taxonomy (Huson and Weber 2013; Huson et al. 2007; Mitra et al. 2011). Multiple genes targeting the same life domain were analyzed separately, and taxa profiles were imported into MEGAN to combine the different analyses into a single profile.

Diversity and statistical analyses were performed after normalizing sequence counts of each taxonomic group by the total number of reads. A taxa table was generated that was used for subsequent statistical analyses. Composition and abundance of microbial taxa were analyzed using PRIMER v7 with the PERMANOVA add-on (Primer-R Ltd., Plymouth, U.K.) (Clarke and Warwick 2001). All species-related data were first standardized whereby relative abundance of each taxa was first subtracted from the mean and then divided by the standard deviation in order to remove differences in total abundance between samples. Data were next transformed to $(\log X+1)$ of relative abundance to down-weight the contribution of the most dominant species before generating Bray-Curtis dissimilarity matrices. An unconstrained ordination using principal coordinates analysis (PCO) combined with cluster analysis was used to determine groupings of diseased and healthy pools at all 
locations. The similarity of these groupings was assessed using a similarity profile test (SIMPROF) (Clarke et al. 2008). These groupings were next compared with a constrained ordination using canonical analysis of principal coordinates (CAP) which maintained an a priori location-disease (LocDis) classification. A Pearson correlation of $>0.4$ was used as an arbitrary threshold to display potential correlations between the abundance of individual taxa and groupings relative to the canonical axes.

Statistical significance was tested through permutational analysis of variance (PERMANOVA) using a nested model with "disease" nested within "location" variable as a fixed factor to determine the level of differences in microbial structure between healthy and diseased pools. If significant $P$ values were obtained from PERMANOVA, an analysis of percentage similarity (SIMPER) was performed to determine the relative contribution of significant taxa distinguishing healthy from diseased pools (Clarke 1993). Mean relative abundances were also obtained for the discriminant taxa.

The Shannon diversity index (H'), Simpson index for community dominance (1-D'), community evenness index (J'), and rarefaction curves were calculated in PAST v.3 package (Hammer et al. 2001). We applied two-way analysis of variance (ANOVA) on diversity indices with sampling location and disease status as the grouping factors to compare means among diseased and healthy pools.

Edaphic factors analyses. Chemical and physical characteristics of soil samples were analyzed individually at Brookside Laboratory (New Bremen, OH). Physical variables included soil type (proportion of clay, silt, and sand) and soil texture. Chemical variables included cation exchange capacity (CEC), organic matter (OM) content, $\mathrm{pH}$, bulk density, Melich III extractable $\mathrm{S}, \mathrm{P}, \mathrm{Ca}, \mathrm{Mg}, \mathrm{K}, \mathrm{Na}, \mathrm{B}$, $\mathrm{Fe}, \mathrm{Mn}, \mathrm{Cu}, \mathrm{Zn}, \mathrm{Al}$, and Bray II P for total organic and available forms of phosphorus in soils (Supplementary Table S1). Other variables included slope average, mean monthly temperatures, and mean monthly precipitations during the growing season (Supplementary Table S2). Multivariate statistical analyses for abiotic variable comparisons between healthy and diseased pools were performed similarly to the biotic data. Measurement data were root-square transformed prior to making Euclidean similarity matrices. However, all abiotic data were first normalized and Euclidean distance-based matrices were generated. We explored potential correlations or impact between the different physical and chemical variables and the incidence of disease at sampling sites by performing ordination and multivariate analyses. The PCO groupings and PERMANOVA analysis were compared
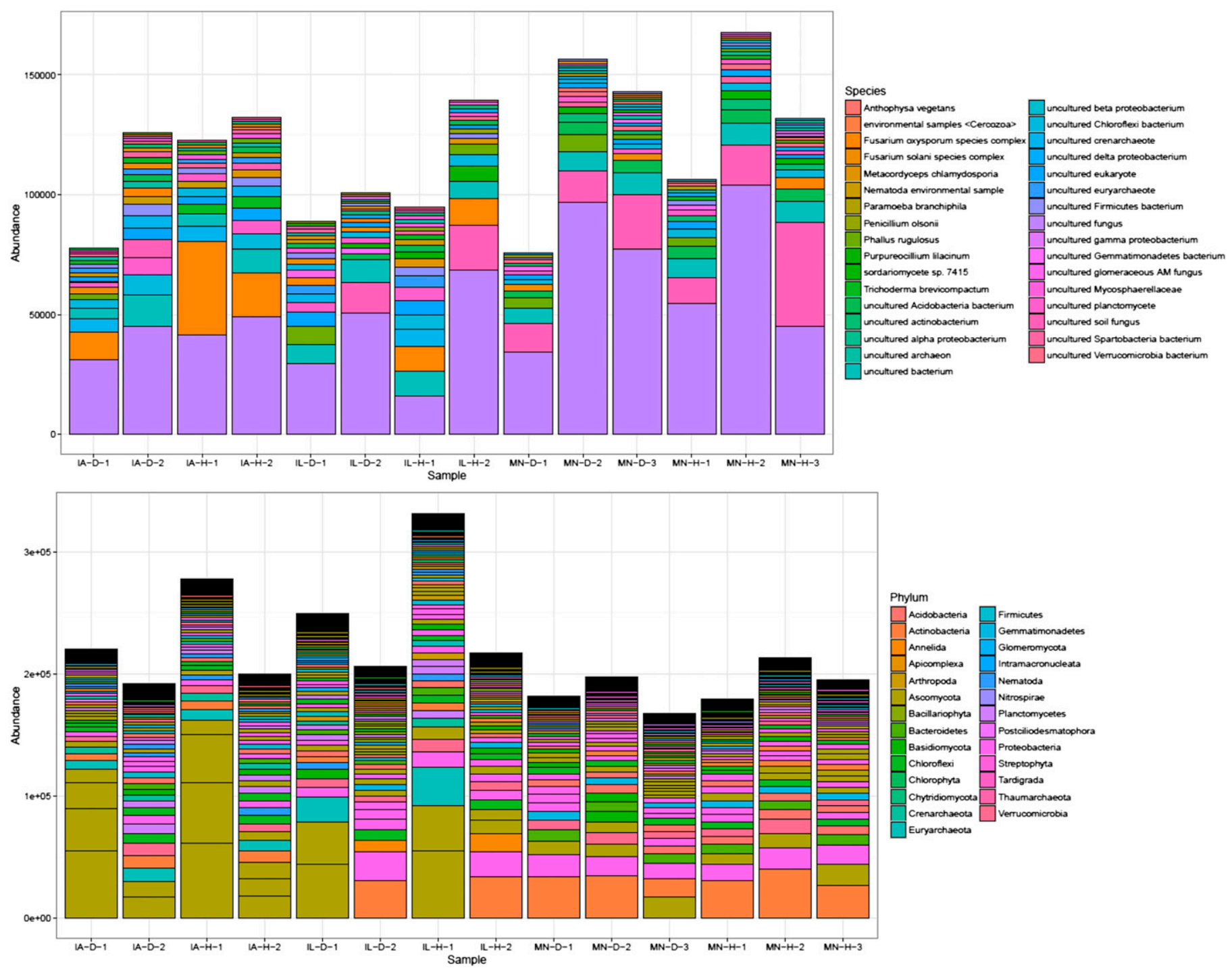

Fig. 2. Abundances of microbial taxa in diseased and healthy pools across sampled locations. Taxa at the lowest common ancestor level (top chart). Taxa at the phylum level (bottom chart). IL, Illinois; IA, lowa; and MN, Minnesota. D, diseased; H, healthy. 
with CAP by maintaining an a priori location $\times$ disease (LocDis) classification.

Quantitative real-time PCR of SDS pathogen. To quantify the SDS pathogen in the sampled soils, we used a probe-based qPCR assay developed at Southern Illinois University and described by Kandel et al. (2015). Populations were quantified in diseased and healthy soils. The assay targeted an IGS region unique to $F$. virguliforme and the closely related Fusarium species known to cause SDS on soybean and other hosts including $F$. azukicola, F. brasiliense, F . crassistipitatum, F. cuneirostrum, F. phaseoli, and F. tucumaniae (Aoki et al. 2012; Hughes et al. 2014). The specific primer pair 5'-GTCAAAATCAGTGTAGGGTAGGT-3', 5'-AC GGGTCGAGACCAGATTT-3' and the ZEN Double-Quenched probe coupled with Fam 5'-TCCGCAAAAATCAGGGCATCCCAC-3' (Integrated DNA Technologies, Inc., Coralville, IA) were used to quantify the absolute amount of $F$. virguliforme DNA in the soil samples. The qPCR was carried out in $20-\mu$ t total reaction volume using GoTaq polymerase (Promega, Madison, WI), with the following thermal profile: $2 \mathrm{~min}$ at $95^{\circ} \mathrm{C}$ followed by 40 cycles of $(15 \mathrm{~s}$ at $95^{\circ} \mathrm{C}$ and $1 \mathrm{~min}$ at $60^{\circ} \mathrm{C}$ ) using a CFX 96 thermocycler (Bio-Rad Laboratories). Each pool was run in three replicates.

Nematode counts. Soil samples from diseased and healthy spots were analyzed to determine population densities of $H$. glycines. Cyst nematodes were extracted from $500 \mathrm{~g}$ of soil via elutriation (Caswell et al. 1985); cysts were counted and crushed using a cyst crusher to enumerate SCN eggs (Faghihi and Ferris 2000).

\section{RESULTS}

Diversity of microbial communities. Of the 14.2 million reads obtained after quality control and filtering, a total of 10.76 million reads were classified into taxa and were found to be associated with the healthy and/or diseased soils across all locations. On average, 768,832 sequence reads were assigned per pool. Sequences were classified into the three major domains, bacteria, archaea, and eukaryota, and to the species level when possible using the LCA algorithm. Most reads were assigned to eukaryota; 58 to $80 \%$ of the reads per pool with 40 to $60 \%$ assigned to kingdom fungi. Bacteria comprised 12 to $33 \%$ of the reads, while archaea had the lowest incidence amounting to 0.6 to $8 \%$ of the reads. These sequences were deposited in NCBI's Sequence Read Archive (SRA) under the accession ID SRP100339. The MEGAN5 pipeline was used to parse blast hits and to examine microbial communities down to the LCA. The distribution and abundance of the microbial communities was estimated at different ranks of the phylogenetic tree, including the species level, whenever reads assignment was possible (Fig. 2).

Taxa number varied between locations and disease status. Samples collected in Illinois hosted the most taxa (mean \pm SE: $220 \pm 3$ taxa per sample), followed by samples collected in Minnesota (186 \pm 17 ), and then those from Iowa (149 \pm 3 ) (Fig. 3). Within the same location (state), diseased and healthy pools shared a large proportion of taxa ( $83 \pm 3 \%$ of taxa). A very small proportion (13 $\pm 2 \%$ of taxa) was found, at any location, to be unique either to diseased or healthy pools. When combined, healthy pools across all locations shared 256 taxa with diseased pools. However, 41 unique taxa were present in either healthy or diseased soils (Fig. 3).

In general, the total number of taxa observed at each location was slightly higher for healthy soils compared with diseased soils (Supplementary Table S3). Two-way ANOVA analysis showed no effect of location or disease factor on either Shannon's species diversity (H') or community evenness (J') (Supplementary Table S4). However, the Simpson index for species dominance was affected by the location factor. All samples were deeply sequenced and showed saturation as evidenced by the rarefaction curves: species accumulation curves exhibited the same number of taxa after increasing the number of sequences beyond 10,000 sequences per sample (Supplementary Fig. S2).

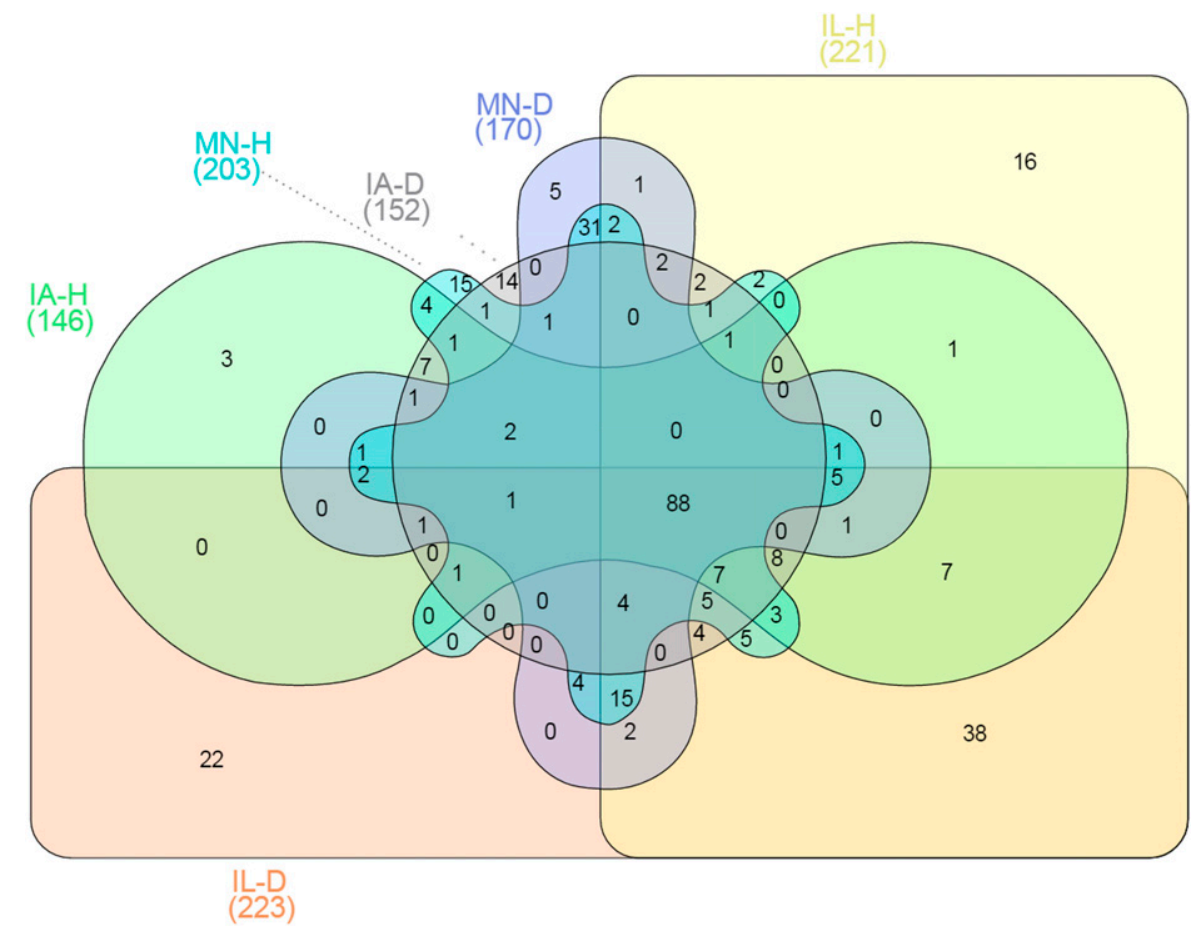

Fig. 3. Venn diagram for taxa assigned at all ranks. Total number of shared and unique taxa identified among diseased and healthy pools: IL-D (Illinois diseased), IL-H (Illinois healthy), IA-D (lowa diseased), IA-H (lowa healthy), MN-D (Minnesota diseased), and MN-H (Minnesota healthy). Overlapping areas show shared taxa among sites. 
Proteobacteria followed by Actinobacteria dominated the bacteria phyla in Illinois and Minnesota. Chloroflexi, Planctomycetes, and Verrucomicrobia were found among the top five phyla in Illinois. In Minnesota, Acidobacteria, Verrucomicrobia, and Chloroflexi ranked among the top five bacterial phyla. In Iowa, Proteobacteria dominated bacterial communities, followed by Planctomycetes, Actinobacteria, Chloroflexi, and Verrucomicrobia, respectively. Ascomycota followed by Basidiomycota dominated fungal communities at all sampling locations (Fig. 2). Stramenopiles were found at all sites, with higher abundance in Minnesota and Illinois than in the Iowa sites.

Microbial taxa comparisons between healthy and diseased soils. Comparisons between diseased and healthy soils revealed differences in microbial community structure and abundance. We assessed differences in taxa using Megan5. A stacked bar chart in Figure 2 shows the percentage of the LCA taxa in both diseased and healthy soils as detected by comparative analysis of phylogenetic trees built for each pool. LCA taxa comprised 102 bacterial, archaeal, fungal, oomycetes, and other eukaryotic species or higher order classes. Bacterial and fungal taxa accounted for more than $80 \%$ of those microbial communities. There were clear differences in differential abundances between healthy and diseased pools among the top LCA taxa (based on the criterion that a specific taxon occurs in $>20 \%$ of all pools).

Microbial structure differed significantly between healthy and diseased pools using PERMANOVA of top taxa at the LCA level. The "disease" nested factor had a significant effect on the community structure in healthy and diseased soils $(P=0.0001)$ (Supplementary Table S5). Using an unconstrained PCO ordination and cluster analysis, soil samples were mainly separated by location (IL, IA, and $\mathrm{MN}$ ) along PCO1, and secondarily by disease status along PCO2 (diseased versus healthy). Healthy soil samples from IL, IA, and $\mathrm{MN}$ were located toward the top of the plot, whereas diseased soils were located toward the bottom of the plot (Fig. 4).

The correlation between the abundance of microbial taxa and disease factor was further confirmed using CAP. CAP plots of biome taxa showed a similar clustering among soils of same disease status: SDS diseased soils were grouped closer together and similarly healthy soils were clustered together at each location (Supplementary Fig. S3).

Similarity percentage analysis (SIMPER) revealed significant bacterial, fungal, and eukaryote compositional differences between healthy and diseased sites. In fact, 39 taxa, representing only $10.6 \%$ of total taxa identified at all sampling sites, accounted for $43.6 \%$ of the discrimination between healthy and diseased pools per SIMPER results. The taxa most associated with the suppression of SDS included fungal and bacterial species that may play a direct role in disease suppression or may enhance plant growth. Overall, dissimilarities were mostly caused by changes in relative abundances rather than presence/absence of the taxa (Fig. 5).

Members of the F. oxysporum species complex, Crenarcheota, Actinomycetales, Chloroflexi, Spartobacteria, Verrucomicrobia, Bradyrhizobiaceae, Planctomycetes, Firmicutes, Pseudomonas, Mycosphearellaceae, Myceliophtora thermophila, Trichoderma harzianum, Trichoderma brevicompactum, Purpureocillium lilacinum, Bolbitaceae, Simplicillium, and Metarhizium were well represented in the healthy soils. In contrast, diseased soils had higher relative abundance of fungal pathogens, plant-pathogenic bacteria, nematodes, and saprophytes. Members of the $F$. solani sp. complex encompassing $F$. virguliforme, F. fujikuroi, Cercomonadidae, Stachybotrys, Rhabditidae, Sordariomycete, Phallus rugulosus, Gemmatimonadetes, and Beta-, Gamma-, and Deltaproteobacteria were more evident in diseased soils. Notably, the $F$. oxysporum $\mathrm{sp}$. complex largely contributed to the suppression of disease in healthy soils (13.34\% contribution) and also exhibited the largest gain in abundance in the healthy community of any taxa. Crenarchaeote and Trichoderma spp. were also among the top contributors in the healthy soils ( $>4 \%$ average contribution). In the diseased soils, Phallus rugulosus, F. solani sp. complex, and Stachybotrys sp. contributed the highest $(7.8,6.3$, and $4.6 \%$, respectively) to the disease incidence in the diseased group (Fig. 5).

Impact of edaphic factors on the distribution and incidence of SDS spots. Edaphic data analyses and SCN counts for healthy and diseased sites are shown in Supplementary Tables S1 and S2. In general, there was no clear or consistent differences among all measured edaphic variables between diseased and healthy spots within the same soybean field. Using PERMANOVA and unconstrained PCO to determine if environmental data and SCN counts shaped groupings of sites by disease incidence, there were no significant differences between diseased and healthy sampling sites based on edaphic variables. Nevertheless, these variables were significantly different across locations $(P=0.0001)$ (Supplementary Table S6). Using an unconstrained PCO coordination based upon Euclidean similarity (Fig. 6), abiotic data and SCN counts of soil samples collected failed to cluster in any evident form. Plots of constrained CAP using abiotic and SCN data were not able to

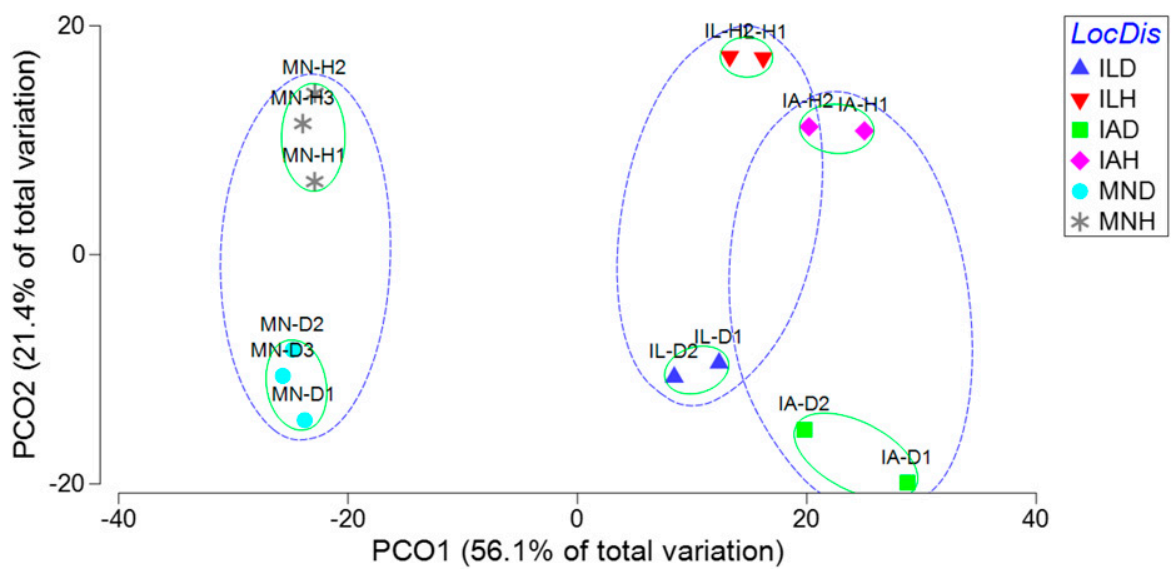

Fig. 4. Principal coordinates ordination (PCO) of the relative abundance of taxa in the diseased versus healthy pools overlayed with SIMPROF cluster analysis (green circles, $80 \%$; and blue circles, 60\% similarity). Soil samples: ILD, Illinois diseased; ILH, Illinois healthy; IAD, Iowa diseased; IAH, Iowa healthy; MND, Minnesota diseased; and MNH, Minnesota healthy. 
distinguish between diseased and healthy soils. However, CAP showed a closer grouping of diseased versus the paired healthy soil from the same location, regardless of the disease variable (Supplementary Fig. S4).

\section{DISCUSSION}

In this study, we examined the phenomenon of SDS patchiness in soybean fields in Illinois, Iowa, and Minnesota. The soil investigated was collected from the rhizosphere and bulk soil of diseased spots in fields as well as healthy spots with no or low levels of SDS. Diseased and healthy soils differed markedly in disease severity despite the presence of $F$. virguliforme in both soils as shown by the qPCR data (Supplementary Fig. S5). The observed reduction of symptoms may be an indication of disease suppression rather than pathogen suppression in the healthy soils. In cases of disease suppression, the inoculum density of the pathogen may or may not be reduced but disease development is restricted (Hoper

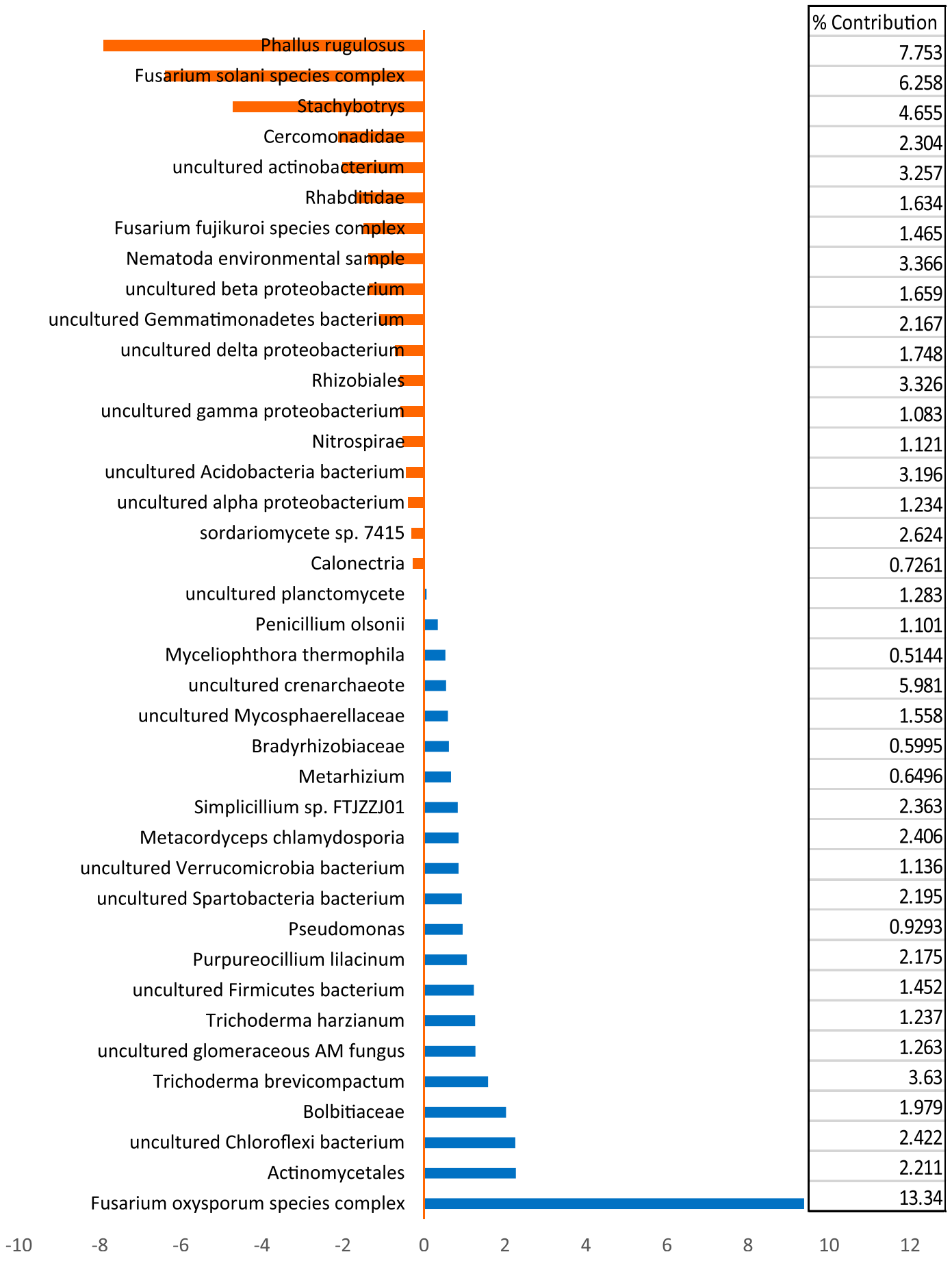

Fig. 5. Similarity percentage analysis (SIMPER). Relative abundance of taxa that contribute to the discrimination between healthy and diseased soils. Mean taxa abundances of healthy soils were subtracted from diseased soils. Taxa that are more abundant in the healthy soils are right of the center axis (blue), while taxa more abundant in diseased soils are left of the center axis (red). Numbers in the right column indicate percent contribution to discrimination by SIMPER analysis. 
and Alabouvette 1996; Weller et al. 2002). There is no study to date that explored the role of microbial communities in SDS incidence or lack of development in soybean fields. The current study provided an initial characterization of the microbiome, assessing the presence of different soil microbial communities, as well as the soybean cyst nematode, in soils where SDS did or did not develop.

Multivariate statistical analyses successfully separated healthy from diseased soils and revealed functional community differences among the two. Moreover, significant differences were more evident in the relative abundance of top LCA taxa rather than in their presence/absence in healthy or diseased soils. These results indicated that SDS incidence or suppression in soils may be more linked to the relative abundance of key microbial taxa rather than in the exclusive presence/absence of specific microbial species. Several other studies on the suppressiveness of soils to bacterial and fungal pathogens have reported similar findings of a significant role of differential community abundance in disease suppression (Mendes et al. 2011; Penton et al. 2014; Rosenzweig et al. 2012; SagovaMareckova et al. 2015).

When comparing microbial communities between diseased and healthy pools assigned at all ranks, we found no differences in richness and diversity using Shannon and Simpson indices. Nevertheless, a few unique taxa were identified. Some of these unique taxa, including Bradyrhizobiaceae, Pseudomonas, Trichoderma harzianum, Stachyborys, Myceliphtora thermophila, and F. fujikuroi species complex, turned to be important indicators of disease status as was revealed later in SIMPER analysis. The rest of the unique taxa were found to be rare i.e., they occurred in one member of the 14 pools but not in the others. The inclusion of rare species would add noise to multivariate analyses, and provide little interpretative value that can be used to infer a direct relation between taxa and SDS development (Bailey et al. 2004; Marchant 1999). These "rare" taxa were therefore excluded from the analysis.

Significant fungal and bacterial differential composition was detected between healthy and diseased pools at each location as well as between locations. MEGAN5 and SIMPER analyses revealed the most dynamic taxa associated with diseased and healthy soil profiles. These taxa largely contained members of bacteria, fungi, and other eukaryotes with SDS pathogen suppression potential. Among bacteria, Actinomycetales, Chloroflexi, Firmicutes, Rhizobiales, and Pseudomonas were more abundant in healthy soils than in diseased soils.

The Actinomycetales were the most dynamic bacterial taxon, and the most consistently abundant bacterial taxon in all soil samples collected from healthy spots. The majority of these identified bacterial taxa are known to be putatively antagonistic to microbes, and have been previously reported to be associated with soils suppressive to diseases (Weller et al. 2002). Members of the family Actinomycetales, particularly the nonpathogenic Streptomyces spp., are known to produce a broad range of antibacterial, antifungal, and nematicidal compounds and were found to be involved in the specific suppression of common scab of potato and Fusarium wilt of strawberry (Bowers et al. 1996; Cha et al. 2016; Mendes et al. 2011; Schottel et al. 2001). Members of this family are also known to produce a heat stable thiopeptide, cyclothiazomycin B1, with antibiotic properties. Cyclothiazomycin B1 has been reported to disrupt the fungal cell wall and to inhibit RNA polymerase (Hashimoto et al. 2006; Mizuhara et al. 2011).

Proteobacteria, including some Rhizobiales and Pseudomonaceae, were the second most abundant bacterial phylum in healthy soils. Plant growth-promoting rhizobacteria (PGPR), in addition to inducing plant growth, have been reported to decrease the activity of plant pathogens via the secretion of antimicrobials and/or effectors that interfere with virulence factors. For example, Pseudomonas spp. produce diacetylphloroglucinol (DAPG), an antifungal compound that has been implicated in soil suppressiveness to Fusarium wilt, and to take-all, diseases caused by the pathogens $F$. oxysporum and Gaeumannomyces graminis, respectively (Haas and Défago 2005; Turner et al. 2013).

Other potential antagonists to SDS included the phyla Firmicutes and Chloroflexi. Both were found to be more represented in healthy soils, particularly in Illinois and Minnesota. Bacillus spp., a key member of the Firmicutes, has been shown to exhibit antifungal activity against $F$. oxysporum and other fungal pathogens via the production of a wide range of metabolites, including chitinases and antifungal peptides (Han et al. 2005; Sharifi Tehrani and Ramezani 2003). Interestingly, among the soil archaeal communities,

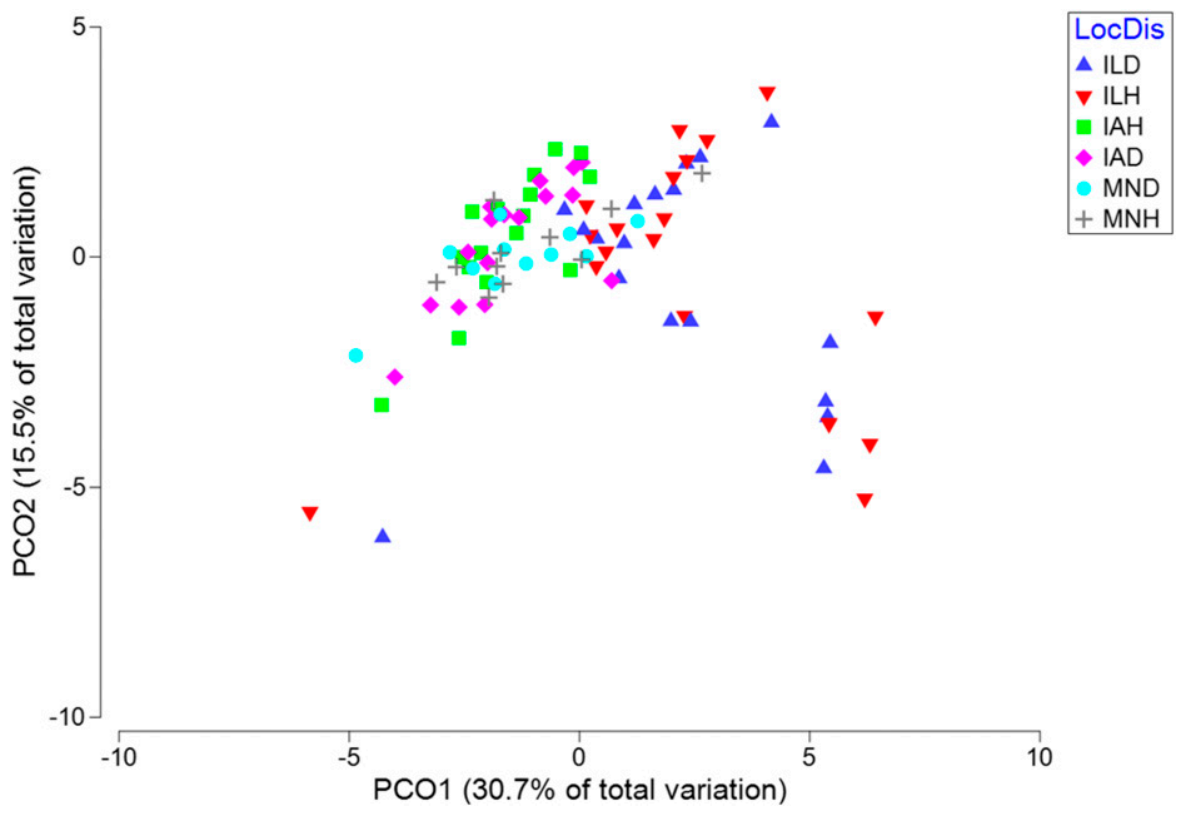

Fig. 6. Principal coordinates ordination (PCO) of edaphic factors measured at all sampling sites. Sites are represented by Location/Disease (LocDis): ILD, Illinois diseased; ILH, Illinois healthy; IAD, lowa diseased; IAH, lowa healthy; MND, Minnesota diseased; and MNH, Minnesota healthy. 
Crenarchaeota largely contributed to healthy soils and were significantly abundant. Crenarchaeota play an important role in carbon and nitrogen cycling in soils, and were also found to oxidize ammonia to nitrite (De La Torre et al. 2008; Konneke et al. 2005).

Most of the fungal taxa associated with healthy soils were present in all soil profiles (healthy and diseased). However, the analysis of relative abundances suggested a potential role of these taxa in SDS suppression. Members of the $F$. oxysporum species complex, Trichoderma spp., Penicillium olsonii, Metacordyceps chlamydosporia, Purpureocillium lilacinum, and Myceliophtora thermophila were highly represented in healthy soils. The $F$. oxysporum species complex was the most abundant fungal taxon associated with healthy soils. Its sequence abundance in healthy soils exceeded that in diseased soils by at least two orders of magnitudes. F. oxysporum occurs frequently in the rhizosphere of plants. While known to cause wilt diseases on plants, it may often subsist in soils as a nonpathogenic saprophyte, suppressing plant pathogens via competition for nutrients and space. Furthermore, in certain instances, $F$. oxysporum has been reported to trigger ISR-based defenses in plants (Fravel et al. 2003).

Two species of Trichoderma, T. harzianum and T. brevicompactum, were found uniquely associated with healthy soils in Illinois and Minnesota, whereas $T$. harzianum was significantly abundant in healthy soils of Iowa. The genus Trichoderma is well known to include a multitude of strains that act antagonistically toward phytopathogens, either directly via antibiosis and mycoparasitism or indirectly by niche exclusion and through the induction of plant defense (Benitez et al. 2004).

Other fungi that showed significant higher abundance in healthy soils included Myceliophtora thermophila, Penicillium olsonii, and Purpureocillium lilacinum. M. thermophila is a thermophilic fungus that produces chitinases. It has been implicated in biomass decomposition, with the ability to hydrolyze all major biomass polysaccharides including cellulose, pectin and xylan (Berka et al. 2011). Purpureocillium lilacinum is a fungal endophyte suggested to improve host plant resistance to nematodes, in exchange for plants providing nutrition and means of transmission to the fungus. Purpureocillium lilacinum is commercially available as a biocontrol agent, mainly to control root-knot nematode and other nematode species including Heterodera spp. (Castillo Lopez et al. 2014; Kannan and Veeravel 2012).

Our data indicate no significant differences in the soil physical and chemical properties between healthy and the paired diseased spot within the same site or field location. We found no correlation between these abiotic variables and SDS suppression and/or incidence. However, the impact of such edaphic factors on the inhibition or expression of SDS is not to be ruled out, as slight differences that might have gone undetected could have an indirect effect on the pathogen and the surrounding microbial community. Further, cyst counts of $H$. glycines suggested that there was no apparent contribution of the nematode population in explaining the high incidence of SDS symptoms in the diseased hotspots. However, our SIMPER analysis on taxa generated from sequencing revealed a potential role of nematodes in disease incidence. While SCN might not be essential in causing the disease, our results suggest a facilitative effect to SDS development when the nematode is present.

Several reports (Cha et al. 2016; Kwak and Weller 2013; Weller et al. 2002) have shown suppressiveness to be induced by long-term continuous monoculturing of a susceptible host. The observed phenomenon of SDS patchiness may be the result of such an induced suppressiveness; the SDS pathogen might have been established in these fields in the past, but with continuous planting of the same crop, soybean plants were able to recruit a synergistic group of more than one biocontrol agent to limit the damage caused by $F$. virguliforme. In this study, at least two groups, Actimomycetales and the F. oxysporum species complex, were found to be consistently associated with healthy soils. A break or an interruption in this long-term induced effect, which can come in the form of crop rotation, tillage, or other practice, might impact the incidence and severity of SDS disease in certain patches of the soybean field.

In summary, the occurrence of SDS hotspots in combination with healthy spots in soybean fields was associated with a consortium of microbial taxa suggesting the importance of certain microbial communities to the establishment and stability of healthy soil. The importance of this study is that it presents the first comprehensive assessment of not just fungal communities, but also of bacterial, oomycetes and nematodes populations composition and structure in SDS-conducive and healthy soils. The maintenance of an equilibrium of diverse microbial communities, driven mainly by the relative abundance of species rather than species inclusion or exclusion, seems to be of critical importance in increasing resiliency of soybean against $F$. virguliforme and establishing a healthy soil. We are beginning to better understand the interplay between diverse species from various life domains, not just in preventing or inducing plant diseases but also in mitigating the effect of antagonistic strains. By decoding the signature profile of SDS-conducive and healthy soils, our study paves the way for further exploration of metagenomes of disease-suppressive soils.

\section{ACKNOWLEDGMENTS}

This work was supported by the United Soybean Board and the North Central Soybean Research Program. All data are publicly available and can be accessed through the Bioproject PRJNA375841 or directly by the NCBI Sequence Read Archive (SRA) under the accession numbers SRP10033.

\section{LITERATURE CITED}

Alabouvette, C. 1986. Fusarium-wilt suppressive soils from the Chateau Renard region: Review of a 10-year study. Agronomie: Sciences des Productions Vegetales et de 1'Environnement 6:273-284.

Aoki, T., O'Donnell, K., Homma, Y., and Lattanzi, A. R. 2003. Sudden-death syndrome of soybean is caused by two morphologically and phylogenetically distinct species within the Fusarium solani species complex $-F$. virguliforme in North America and F. tucumaniae in South America. Mycologia 95: 660-684.

Aoki, T., O'Donnell, K., and Scandiani, M. M. 2005. Sudden death syndrome of soybean in South America is caused by four species of Fusarium: Fusarium brasiliense sp. nov., F. cuneirostrum sp. nov., F. tucumaniae, and F. virguliforme. Mycoscience 46:162-183.

Aoki, T., Tanaka, F., Suga, H., Hyakumachi, M., Scandiani, M. M., and O’Donnell, K. 2012. Fusarium azukicola sp. nov., an exotic azuki bean rootrot pathogen in Hokkaido, Japan. Mycologia 104:1068-1084.

Bailey, R. C., Norris, R. H., and Reynoldson, T. B. 2004. Bioassessment of Freshwater Ecosystems: Using the Reference Condition Approach. Springer, New York.

Baker, K. F., and Cook, R. J. 1982. Biological Control of Plant Pathogens. American Phytopathological Society, St. Paul, MN.

Bakkeren, G., Kronstad, J. W., and Lévesque, C. A. 2000. Comparison of AFLP fingerprints and ITS sequences as phylogenetic markers in Ustilaginomycetes. Mycologia 92:510-521.

Benitez, T., Rincon, A. M., Limon, M. C., and Codon, A. C. 2004. Biocontrol mechanisms of Trichoderma strains. Int. Microbiol. 7:249-260.

Bergmann, G. T., Walters, W. A., Knight, R., Fierer, N., Caporaso, J. G., Bates, S. T., Eilers, K. G., and Lauber, C. L. 2011. The under-recognized dominance of Verrucomicrobia in soil bacterial communities. Soil Biol. Biochem. 43: 1450-1455.

Berka, R. M., Grigoriev, I. V., Otillar, R., Salamov, A., Grimwood, J., Reid, I., Ishmael, N., John, T., Darmond, C., Moisan, M.-C., Henrissat, B., Coutinho, 
P. M., Lombard, V., Natvig, D. O., Lindquist, E., Schmutz, J., Lucas, S., Harris, P., Powlowski, J., Bellemare, A., Taylor, D., Butler, G., de Vries, R. P., Allijn, I. E., van den Brink, J., Ushinsky, S., Storms, R., Powell, A. J., Paulsen, I. T., Elbourne, L. D. H., Baker, S. E., Magnuson, J., LaBoissiere, S., Clutterbuck, A. J., Martinez, D., Wogulis, M., de Leon, A. L., Rey, M. W., and Tsang, A. 2011. Comparative genomic analysis of the thermophilic biomass-degrading fungi Myceliophthora thermophila and Thielavia terrestris. Nat. Biotechnol. 29:922-927.

Blaxter, M. 1998. Caenorhabditis elegans is a nematode. Science 282:2041.

Bowers, J. H., Kinkel, L. L., and Jones, R. K. 1996. Influence of diseasesuppressive strains of Streptomyces on the native Streptomyces community in soil as determined by the analysis of cellular fatty acids. Can. J. Microbiol. 42:27-37.

Broadbent, P., and Baker, K. F. 1974. Behavior of Phytophthora cinnamomi in soils suppressive and conducive to root rot. Aust. J. Agric. Res. 25:121.

Castillo Lopez, D., Zhu-Salzman, K., Ek-Ramos, M. J., and Sword, G. A. 2014. The entomopathogenic fungal endophytes Purpureocillium lilacinum (formerly Paecilomyces lilacinus) and Beauveria bassiana negatively affect cotton aphid reproduction under both greenhouse and field conditions. PLoS One 9:e103891.

Caswell, E. P., McKinney, H. E., and Thomason, I. J. 1985. Extraction of cysts and eggs of Heterodera schachtii from soil with an assessment of extraction efficiency. J. Nematol. 17:337-340.

Cha, J. Y., Han, S., Hong, H. J., Cho, H., Kim, D., Kwon, Y., Kwon, S. K., Crusemann, M., Bok Lee, Y., Kim, J. F., Giaever, G., Nislow, C., Moore, B. S., Thomashow, L. S., Weller, D. M., and Kwak, Y. S. 2016. Microbial and biochemical basis of a Fusarium wilt-suppressive soil. ISME J. 10: 119-129.

Chen, S. Y. 2007. Suppression of Heterodera glycines in soils from fields with long-term soybean monoculture. Biocontrol Sci. Technol. 17:125-134.

Chet, I., and Baker, R. 1980. Induction of suppressiveness to Rhizoctonia solani in soil. Phytopathology 70:994-998.

Clarke, K. R. 1993. Non-parametric multivariate analyses of changes in community structure. Aust. J. Ecol. 18:117-143.

Clarke, K. R., Somerfield, P. J., and Gorley, R. N. 2008. Testing of null hypotheses in exploratory community analyses: Similarity profiles and biotaenvironment linkage. J. Exp. Mar. Biol. Ecol. 366:56-69.

Clarke, K. R., and Warwick, R. M. 2001. Change in marine communities: An approach to statistical analysis and interpretation. PRIMER-E Ltd., Plymouth.

Cook, R. J., and Rovira, A. D. 1976. The role of bacteria in the biological control of Gaeumannomyces graminis by suppressive soils. Soil Biol. Biochem. 8:269-273.

Curl, E. 1963. Control of plant diseases by crop rotation. Bot. Rev. 29:413.

De La Torre, J. R., Walker, C. B., Ingalls, A. E., Könneke, M., and Stahl, D. A. 2008. Cultivation of a thermophilic ammonia oxidizing archaeon synthesizing crenarchaeol. Environ. Microbiol. 10:810-818.

Faghihi, J., and Ferris, J. M. 2000. An efficient new device to release eggs from Heterodera glycines. J. Nematol. 32:411-413.

Fravel, D., Olivain, C., and Alabouvette, C. 2003. Fusarium oxysporum and its biocontrol. New Phytol. 157:493-502.

Gao, X., Jackson, T. A., Hartman, G. L., and Niblack, T. L. 2006. Interactions between the soybean cyst nematode and Fusarium solani f. sp. glycines based on greenhouse factorial experiments. Phytopathology 96:1409-1415.

Geiser, D. M., Jimenez-Gasco, M. D., Kang, S. C., Makalowska, I., Veeraraghavan, N., Ward, T. J., Zhang, N., Kuldau, G. A., and O'Donnell, K. 2004. FUSARIUM-ID v. 1.0: A DNA sequence database for identifying Fusarium. Eur. J. Plant Pathol. 110:473-479.

Gongora-Canul, C. C., and Leandro, L. F. S. 2011. Effect of soil temperature and plant age at time of inoculation on progress of root rot and foliar symptoms of soybean sudden death syndrome. Plant Dis. 95:436-440.

Gray, L. E., and Achenbach, L. A. 1996. Severity of foliar symptoms and root and crown rot of soybean inoculated with various isolates and inoculum rates of Fusarium solani. Plant Dis. 80:1197-1199.

Haas, D., and Défago, G. 2005. Biological control of soil-borne pathogens by fluorescent pseudomonads. Nat. Rev. Microbiol. 3:307-319.

Hammer, Ø., Harper, D. A. T., and Ryan, P. D. 2001. PAST: Paleontological statistics software package for education and data analysis. Palaeontologia Electronica 4:9.

Han, J. S., Cheng, J. H., Yoon, T. M., Song, J., Rajkarnikar, A., Kim, W. G., Yoo, I. D., Yang, Y. Y., and Suh, J. W. 2005. Biological control agent of common scab disease by antagonistic strain Bacillus sp. sunhua. J. Appl. Microbiol. 99:213-221.

Hartman, G. L., Bowen, C. R., Haudenshield, J. S., Fox, C. M., Cary, T. R., and Diers, B. W. 2015a. Evaluation of disease and pest damage on soybean cultivars released from 1923 through 2008 under field conditions in central Illinois. Agron. J. 107:2373-2380.

Hartman, G. L., Chang, H. X., and Leandro, L. F. 2015b. Research advances and management of soybean sudden death syndrome. Crop Prot. 73:60-66.

Hashimoto, M., Murakami, T., Funahashi, K., Tokunaga, T., Nihei, K.-i., Okuno, T., Kimura, T., Naoki, H., and Himeno, H. 2006. An RNA polymerase inhibitor, cyclothiazomycin B1, and its isomer. Bioorg. Med. Chem. 14:8259-8270.

Hoper, H., and Alabouvette, C. 1996. Importance of physical and chemical soil properties in the suppressiveness of soils to plant diseases. Eur. J. Soil Biol. 32:41-58.

Howard, D. D., Chambers, A. Y., Brawley, P. W., and Bush, T. D. 1992. Fertilization effects on soybean sudden death syndrome. Better Crops Plant Food 77:14-15.

Hughes, T. J., O’Donnell, K., Sink, S., Rooney, A. P., Scandiani, M. M., Luque, A., Bhattacharyya, M. K., and Huang, X. Q. 2014. Genetic architecture and evolution of the mating type locus in fusaria that cause soybean sudden death syndrome and bean root rot. Mycologia 106:686-697.

Huson, D. H., Auch, A. F., Qi, J., and Schuster, S. C. 2007. MEGAN analysis of metagenomic data. Genome Res. 17:377-386.

Huson, D. H., and Weber, N. 2013. Microbial community analysis using MEGAN. Methods Enzymol. 531:465-485.

Islam, K. T., Bond, J. P., Riggs, J., and Fakhoury, A. M. 2015. Impact of ILeVO on the infection and colonization of soybean roots by Fusarium virguliforme. The American Phytopathological Society Annual Meeting, Pasadena, CA.

James, T. Y., Letcher, P. M., Longcore, J. E., Mozley-Standridge, S. E., Porter, D., Powell, M. J., Griffith, G. W., and Vilgalys, R. 2006. A molecular phylogeny of the flagellated fungi (Chytridiomycota) and description of a new phylum (Blastocladiomycota). Mycologia 98:860-871.

Kandel, Y. R., Haudenshield, J. S., Srour, A. Y., Islam, K. T., Fakhoury, A. M., Santos, P., Wang, J., Chilvers, M. I., Hartman, G. L., Malvick, D. K., Floyd, C. M., Mueller, D. S., and Leandro, L. F. 2015. Multilaboratory comparison of quantitative PCR assays for detection and quantification of Fusarium virguliforme from soybean roots and soil. Phytopathology 105:1601-1611.

Kannan, R., and Veeravel, R. 2012. Effect of different dose and application methods of Paecilomyces lilacinus (Thom.) Samson against root knot nematode, Meloidogyne incognita (Kofoidand White) Chitwood in okra. J. Agric. Sci. 4:119.

Kantartzi, S. K., Klein, J., and Schmidt, M. 2012. Registration of 'Saluki 4411' soybean with resistance to sudden death syndrome and HG type 0 (race 3) soybean cyst nematode. J. Plant Registrations 6:298-301.

Kloepper, J. W., Rodriguez-Kabana, R., Zehnder, G. W., Murphy, J. F., Sikora, E., and Fernandez, C. 1999. Plant root-bacterial interactions in biological control of soilborne diseases and potential extension to systemic and foliar diseases. Australas. Plant Pathol. 28:21-26.

Kok, C. J., Papert, A., and Hok-A-Hin, C. H. 2001. Microflora of Meloidogyne egg masses: Species composition, population density and effect on the biocontrol agent Verticillium chlamydosporium (Goddard). Nematology 3:729-734.

Konneke, M., Bernhard, A. E., de la Torre, J. R., Walker, C. B., Waterbury, J. B., and Stahl, D. A. 2005. Isolation of an autotrophic ammonia-oxidizing marine archaeon. Nature 437:543-546.

Kwak, Y. S., and Weller, D. M. 2013. Take-all of wheat and natural disease suppression: A review. Plant Pathol. J. 29:125-135.

Leandro, L. F., Tatalovic, N., and Luckew, A. 2012. Soybean sudden death syndromeAdvances in knowledge and disease management. CAB Rev. 7:1-14.

Lévesque, C. A., and De Cock, A. W. A. M. 2004. Molecular phylogeny and taxonomy of the genus Pythium. Mycol. Res. 108:1363-1383.

Li, S., Hartman, G. L., and Chen, Y. 2009. Evaluation of aggressiveness of Fusarium virguliforme isolates that cause soybean sudden death syndrome. J. Plant Pathol. 91:77-86.

Malvick, D. K., and Bussey, K. E. 2008. Comparative analysis and characterization of the soybean sudden death syndrome pathogen Fusarium virguliforme in the northern United States. Can. J. Plant Pathol.-Rev. Can. Phytopathol. 30:467-476.

Marchant, R. 1999. How important are rare species in aquatic community ecology and bioassessment? A comment on the conclusions of Cao et al. Limnol. Oceanogr. 44:1840-1842.

Mazzola, M. 2002. Mechanisms of natural soil suppressiveness to soilborne diseases. Antonie van Leeuwenhoek 81:557-564.

Mazzola, M. 2004. Assessment and management of soil microbial community structure for disease suppression. Annu. Rev. Phytopathol. 42:35-59.

McLean, K. S., and Lawrence, G. W. 1995. Development of Heterodera glycines as affected by Fusarium solani, the causal agent of sudden death syndrome of soybean. J. Nematol. 27:70-77. 
Mendes, R., Kruijt, M., de Bruijn, I., Dekkers, E., van der Voort, M., Schneider, J. H., Piceno, Y. M., DeSantis, T. Z., Andersen, G. L., Bakker, P. A., and Raaijmakers, J. M. 2011. Deciphering the rhizosphere microbiome for disease-suppressive bacteria. Science 332:1097-1100.

Mitra, S., Stark, M., and Huson, D. H. 2011. Analysis of 16S rRNA environmental sequences using MEGAN. BMC Genomics 12(Suppl. 3):S17.

Mizuhara, N., Kuroda, M., Ogita, A., Tanaka, T., Usuki, Y., and Fujita, K.-I. 2011. Antifungal thiopeptide cyclothiazomycin B1 exhibits growth inhibition accompanying morphological changes via binding to fungal cell wall chitin. Bioorg. Med. Chem. 19:5300-5310.

Murakami, H., Tsushima, S., and Shishido, Y. 2000. Soil suppressiveness to clubroot disease of Chinese cabbage caused by Plasmodiophora brassicae. Soil Biol. Biochem. 32:1637-1642.

Muyzer, G., de Waal, E. C., and Uitterlinden, A. G. 1993. Profiling of complex microbial populations by denaturing gradient gel electrophoresis analysis of polymerase chain reaction-amplified genes coding for 16S rRNA. Appl. Environ. Microbiol. 59:695-700.

Nishiyama, M., Shiomi, Y., Suzuki, S., and Marumoto, T. 1999. Suppression of growth of Ralstonia solanacearum, tomato bacterial wilt agent, on/in tomato seedlings cultivated in a suppressive soil. Soil Sci. Plant Nutr. 45:79-87.

Njiti, V. N., Doubler, T. W., Suttner, R. J., Gray, L. E., Gibson, P. T., and Lightfoot, D. A. 1998. Resistance to soybean sudden death syndrome and root colonization by Fusarium solani f. sp. glycine in near-isogenic lines. Crop Sci. 38:472-477.

Nunn, G. B., Theisen, B. F., Christensen, B., and Arctander, P. 1996. Simplicitycorrelated size growth of the nuclear 28S ribosomal RNA D3 expansion segment in the crustacean order Isopoda. J. Mol. Evol. 42:211-223.

Penton, C. R., Gupta, V. V. S. R., Tiedje, J. M., Neate, S. M., Ophel-Keller, K., Gillings, M., Harvey, P., Pham, A., and Roget, D. K. 2014. Fungal community structure in disease suppressive soils assessed by $28 \mathrm{~S}$ LSU gene sequencing. PLoS One 9:e93893.

Persson, L., Larsson-Wikström, M., and Gerhardson, B. 1999. Assessment of soil suppressiveness to Aphanomyces root rot of pea. Plant Dis. 83:1108-1112.

Pyrowolakis, A., Westphal, A., Sikora, R. A., and Ole Becker, J. 2002. Identification of root-knot nematode suppressive soils. Appl. Soil Ecol. 19:51-56.

Rosenzweig, N., Tiedje, J. M., Quensen, J. F., Meng, Q. X., and Hao, J. J. J. 2012. Microbial communities associated with potato common scabsuppressive soil determined by pyrosequencing analyses. Plant Dis. 96: 718-725.

Roy, K. W., Rupe, J. C., Hershman, D. E., and Abney, T. S. 1997. Sudden death syndrome of soybean. Plant Dis. 81:1100-1111.

Rupe, J. C., and Gbur, E. E., Jr. 1995. Effect of plant age, maturity group, and the environment on disease progress of sudden death syndrome of soybean. Plant Dis. 79:139-143.

Rupe, J. C., Robbins, R. T., and Gbur, E. E. 1997. Effect of crop rotation on soil population densities of Fusarium solani and Heterodera glycines and on the development of sudden death syndrome of soybean. Crop Prot. 16: 575-580.

Rupe, J. C., Sabbe, W. E., Robbins, R. T., and Gbur, E. E., Jr. 1993. Soil and plant factors associated with sudden death syndrome of soybean. J. Prod. Agric. 6:218-221.

Ryan, P. R., Dessaux, Y., Thomashow, L. S., and Weller, D. M. 2009.

Rhizosphere engineering and management for sustainable agriculture. Plant Soil 321:363-383.
Sagova-Mareckova, M., Daniel, O., Omelka, M., Kristufek, V., Divis, J., and Kopecky, J. 2015. Determination of factors associated with natural soil suppressivity to potato common scab. PLoS One 10:e0116291.

Sanogo, S., and Yang, X. B. 2001. Relation of sand content, pH, and potassium and phosphorus nutrition to the development of sudden death syndrome in soybean. Can. J. Plant Pathol. 23:174.

Scherm, H., and Yang, X. B. 1999. Article: Risk assessment for sudden death syndrome of soybean in the north-central United States. Agric. Syst. 59: 301-310.

Scherm, H., Yang, X. B., and Lundeen, P. 1998. Soil variables associated with sudden death syndrome in soybean fields in Iowa. Plant Dis. 82:1152-1157.

Schottel, J. L., Shimizu, K., and Kinkel, L. L. 2001. Relationships of in vitro pathogen inhibition and soil colonization to potato scab biocontrol by antagonistic Streptomyces spp. Biol. Control 20:102-112.

Sharifi Tehrani, A., and Ramezani, M. 2003. Biological control of Fusarium oxysporum, the causal agent of onion wilt by antagonistic bacteria. Communications Agric. Appl. Biol. Sci. 68:543-547.

Srour, A. Y., Fakhoury, A. M., and Brown, R. L. 2017. Targeting aflatoxin biosynthetic genes. Pages 159-171 in: Mycotoxigenic Fungi: Methods and Protocols. A. Moretti and A. Susca, eds. Springer, New York.

Turner, T. R., James, E. K., and Poole, P. S. 2013. The plant microbiome. Genome Biol. 14:209.

Vick, C. M., Bond, J. P., Chong, S. K., and Russin, J. S. 2006. Response of soybean sudden death syndrome to tillage and cultivar. Can. J. Plant Pathol.Rev. Can. Phytopathol. 28:77-83.

Vilgalys, R., and Hester, M. 1990. Rapid genetic identification and mapping of enzymatically amplified ribosomal DNA from several Cryptococcus species. J. Bacteriol. 172:4238-4246.

Weibelzahl-Fulton, E., Dickson, D. W., and Whitty, E. B. 1996. Suppression of Meloidogyne incognita and $M$. javanica by Pasteuria penetrans in field soil. J. Nematol. 28:43-49.

Weller, D. M., Raaijmakers, J. M., Gardener, B. B., and Thomashow, L. S. 2002. Microbial populations responsible for specific soil suppressiveness to plant pathogens. Annu. Rev. Phytopathol. 40:309-348.

Westphal, A., and Becker, J. O. 2001. Components of soil suppressiveness against Heterodera schachtii. Soil Biol. Biochem. 33:9-16.

Westphal, A., and Xing, L. J. 2011. Soil suppressiveness against the disease complex of the soybean cyst nematode and sudden death syndrome of soybean. Phytopathology 101:878-886.

White, T., Bruns, T., Lee, S., and Taylor, J. 1990. Amplification and direct sequencing of fungal ribosomal RNA genes for phylogenetics. Pages 315-322 in: PCR Protocols: A Guide to Methods and Applications. M. Innis, D. Gelfand, J. Shinsky, and T. White, eds. Academic Press, Cambridge, MA.

Wrather, A., and Koenning, S. 2009. Effects of diseases on soybean yields in the United States 1996 to 2007. Plant Health Progress. Published online. doi: 10.1094/PHP-2009-0401-01-RS

Wrather, J. A., and Koenning, S. R. 2006. Estimates of disease effects on soybean yields in the United States 2003 to 2005. J. Nematol. 38:173-180.

Xing, L. J., and Westphal, A. 2009. Effects of crop rotation of soybean with corn on severity of sudden death syndrome and population densities of Heterodera glycines in naturally infested soil. Field Crops Res. 112:107-117.

Xing, L. J., and Westphal, A. 2013. Synergism in the interaction of Fusarium virguliforme with Heterodera glycines in sudden death syndrome of soybean. J. Plant Dis. Prot. 120:209-217.

Zhang, Z., Schwartz, S., Wagner, L., and Miller, W. 2000. A greedy algorithm for aligning DNA sequences. J. Comput. Biol. 7:203-214. 